\title{
TOWARDS THEORETICAL MODELING OF THE SAND DUNES MOTION
}

\author{
O.I. Gerasymov, Dr. Sci. (Phys.-Math), \\ I.S. Andrianova, Cand. Sci. (Phys.-Math.) \\ Odessa State Environmental University, . \\ Lvivska str. 15, 65016, Odessa,Ukraine, gerasymovoleg@gmail.com
}

\begin{abstract}
The transport of sand by wind is a potent erosion force, creates sand dunes and ripples, and loads the atmosphere with suspended dust aerosols. This article presents a short review of the physics of wind-driven sand. Specifically, we review the physics of saltation, the formation and development of sand dunes and ripples. We also discuss some classes of the governing equations which describe the physics of wind-driven sand and dune formation. We describe selected types of dunes and conditions under which they occur, and also some features of dunes as well as processes that they are involved in. We show that the normalized dunes height collapses using a simple product of the Froude and Reynolds numbers. This would obscure the effects of frictional dissipation, which clearly plays an important role in all mentioned upper process. Ignoring friction, one can construct a simple energy balance between the kinetic energy of the impacting $\rho_{b} D_{b}^{3} U^{2}$ and the potential energy of the dunes $\rho_{s} g d_{s}^{2} H_{j}^{2}$, where we assume the dunes thickness is proportional to $d_{s}$. This produces the following scaling $H_{j} / D_{b} \propto r_{p} \operatorname{Fr} \sqrt{\mathrm{Re}}$.

In other words, was one to increase the grain diameter $d_{s}$ by a factor of $10 \sim$ i.e., reduce Re by 100 ! for the same impact conditions, then the frictionless flow would predict a 10 -fold reduction in $H_{j}$, whereas the experiments suggest a 100 -fold reduction. This shows clearly that viscous forces play a role in the granular dunes formation (and their relevant dynamics), as well as gravity and inertia.

These circumstances move us to conclude the vide range of (non-dissipative) hydrodynamic approaches to describe dunes formation and their dynamics just as a robust model approaches.
\end{abstract}

Key words: sand dunes, wind flow, shear stress, granular viscosity.

\section{INTRODUCTION}

Dunes are found wherever a fluid interacts with an erodible bed beneath it, whether this is in the familiar context of sand in a desert blown by the force of the wind, the silt on the bed of a river being eroded by the water flowing over it, or drifts formed by the action of wind on powdery snow. The ubiquity of these repetitive, wavelike features suggests that there is an inherent instability making it impossible for a horizontal bed to stay horizontal, and that there is an underlying reason, predictable by analytic study of the processes involved, that causes such features to form in a wide variety of circumstances, and on a number of different scales.

The interaction between a fluid and an erodible substrate beneath it is a complex one. The flow of water in a river and the flow of wind in the atmosphere are always turbulent, making analytical study difficult. Similarly the behavior of granular flow is complex and only partially understood. These two mechanisms in turn affect each other, since the fluid exerts a force on the substrate, causing it to be eroded, and thereby changing its shape, whereas the shape of the bed in turn influences the characteristics of the flow of the fluid over it. It is the understanding of this feedback mechanism that is the goal of any study of dune formation, and it is for these reasons that previous studies have been only partially successful in predicting the formation, evolution, and migration of dunes in a general framework.
We conclude this paper by reviewing some of the existing work that has been undertaken on this subject. The remainder of the papers then concerned with the discussion of deterministic models for the formation and subsequent evolution of dunes. We will discuss a set of an alternative method of calculating the surface shear stress, the derivation being based on theories of wind flow rather than the theories of river flow. We consider the concept that a small perturbation to the lower boundary (corresponding to a dune) has to the logarithmic velocity profile of the flow of wind over a horizontal boundary.

At this point the theory assumes that there is no flow separation occurring (i.e. that there are no wake regions present) in any part of the flow. Since flow separation is a ubiquitous process in the turbulent flow of air over an uneven boundary, we go on to consider an existing, heuristic, method of modeling the phenomenon of flow. A wide variety of dune shapes can be seen in deserts the occurrence of different types depending on various conditions such as sand supply, particle size, wind direction, vegetation, etc. Dunes occurring under rivers show less variety in their form. This is because the flow of water in a river is much simpler than the flow of wind in a desert - the flow is restricted to the channel of the river, and while the flow is not truly two-dimensional, the downstream flow is much larger in magnitude than the cross-stream component. 
In both cases, dunes form because of the action of the fluid upon the substrate. The stress force associated with the shear flow acts on the particles, causing them either to be entrained into the flow (and subsequently be deposited elsewhere) or to move along the surface. The shear stress thus changes the profile of the underlying surface, but the shear stress itself depends on the bed profile, so there is a feedback mechanism between the two.

\section{SOME GENERAL DEFINITIONS}

Aeolian dunes are dunes formed by the action of wind on desert sand, the name coming from the mythical god of the winds, Aeolus. Aeolian dunes show a massive variety of forms, which arise both from the nature of the sand of which they consist, and from the patterns of air movement which cause them to exist. Sand is defined by Bagnold [1] as being any particle with a diameter of between $0.02 \mathrm{~mm}$ and $1 \mathrm{~mm}$. Obviously particles in general are not spherical so that a unique diameter does not exist; instead we consider a typical diameter of the particle, for example the mean of the diameter in a number of different directions. The motivation for this definition comes from the behavior of particles under the action of wind.

The smallest sand particles are those which are not carried away by the wind and are those which are so large that they only just move, either from the force of the wind blowing over them, or because of the impact of other particles on them. The particles which fall into this range are hence the only particles which, under the influence of wind, exhibit self-accumulation. These particles use the energy of the wind to collect together and form heaps, commonly called dunes, which can retain their identity, move from place to place, pile up, elongate, and combine with other dunes, always forming regular patterns.

The above definition does not specify the material from which particles of sand are made. Therefore any sort of rock can be classified as being sand provided it is the right size, similarly for particles of plastic, metals, etc. The ice crystals of snow also fall into this size range and are therefore defined as sand. It turns out that the only characteristic of sand particles which has a significant effect on the dynamics is the particle size. Other factors such as the material or the weight of the particle have much smaller effects on, for example, the formation of ripples and dunes. For example, two particles made of the same material, one twice as heavy as the other, will only differ in grain diameter by 1.26 times. For this reason, drifting snow behaves in a very similar way to desert sand dunes.

However, despite the very broad definition of sand given above, the common perception of sand is much more specific, namely particles of quartz silica. The reason for this is that for most materials, particles which are classified as sand are unstable; they do not remain in this form for very long. Particles of rocks other than quartz tend to get smaller due to collisions with each other under the action of wind and water. Similarly snowflakes soon turn into either ice, or water, or vapor. Quartz, on the other hand, is much longer-lasting, as it resists the action of chemicals, is not soluble in water, and is not generally susceptible to abrasion or fracture. In other words, quartz sand particles are stable; they tend to remain in essentially the same form for substantial periods of time. The biggest sand particles scattered as dust, i.e. they are sufficiently large that when picked up by the wind, they return to the ground in a reasonable amount of time.

We describe selected types of dunes and conditions under which they occur, and also some features of dunes as well as processes that they are involved in. The common view of deserts is of landscapes dominated by sand dunes, but in fact only between one third and one quarter of the world's deserts is covered by Aeolian sand. In particular, sand dunes only make up $1 \%$ of the surface area of the Earth.

\section{DETERMINISTIC DYNAMICS OF MODEL SAN DUNES}

To keep the steady movement of dunes there has to be a source which carries the energy to move sand over the surface. The shear stress of the air flow in the atmospheric boundary layer can force sediments to be entrained. The crucial question to know is the flow over dunes situated in a laminar or a turbulent regime? Formally, the familiar Reynolds Re number gives necessary estimation. Note that it consists of the ratio between inertial and viscous forces

$$
\mathrm{Re}=\frac{\rho \mathrm{v}^{2} / L}{\mu \mathrm{v} / L}=\frac{L \mathrm{v}}{\mathrm{v}},
$$

where $\rho$ denotes the density of the fluid, $L$ - a characteristic length, $\mathrm{v}$ - a characteristic wind velocity, $\mu-$ the viscosity of the fluid and $v=\mu / \rho-$ the kinematic viscosity. If the inertial forces dominate the viscous force the regime gets turbulent and the Reynolds number should becomes significantly greater than 1 . We address the question: do exist the scaling of the objects which is of the height of a dune? The relevant calculations performed in case of typical sand dunes leads to a high Reynolds number of about 6000 [2]. Therefore, even small wind speeds formally should create turbulent flows. Turbulent flow means randomly directed and distributed fluctuations and eddies. The shear stresses of turbulent flow are much higher than of laminar flow. Following, for instance, to the mixing length theory [3] turbulent shear stress can be written as 


$$
\tau_{T}=\eta \frac{d \mathrm{v}}{d z}=\rho l^{2}\left(\frac{d \mathrm{v}}{d z}\right)^{2},
$$

where $\eta$ is a turbulent viscosity and 1 the mixing length. At global turbulent flows the dynamic viscosity $\mu$ gets much smaller than the turbulent viscosity $\eta$. Thus the former viscosity can be neglected. Assuming that the mixing length increases linearly with the distance from the surface $1=\mathrm{kz}(k \approx 0,4$ is the von Kármán universal constant for turbulent flow), after integration from $z_{0}$ to $z$ of equation (2) one can obtain familiar logarithmic profile of the atmospheric boundary layer

$$
\mathrm{v}(z)=\frac{u_{*}}{k} \ln \frac{z}{z_{0}},
$$

$z_{0}$ has the meaning of a roughness length. One can introduce the thickness of the laminar sub-layer which characterize aerodynamically smooth surface (or the size of surface perturbation for aerodynamically rough surface), relevant velocity scale $u_{*}=\sqrt{\tau / \rho}$, can be called shear stress velocity. Although it has the dimension of a velocity the shear velocity $u_{*}$ anyhow can be used as a measure for the shear stress.

Consider now the main properties of sand. There are grain diameter $\mathrm{d}$, shape and the material of which the grains consist. Following to [4] we can introduce an approximate classification ranges from large sand grain (coarse) with diameter $\mathrm{d}=2 \mathrm{~mm}$ to small (fine sand) with diameter $d \approx 0.063 \mathrm{~mm}$. In practice sand grains are composed of a big variety of shapes. According to [5] it is classified into "well rounded", "angular", "platy", "elongated", or "compact". Mostly sand grains consist of quartz $\left(\mathrm{SiO}_{2}\right)$ which has a density of $\rho_{\text {quartz }}=2650 \mathrm{~kg} \cdot \mathrm{m}^{-3}$. In [5] it has been shown that sand grains of dune fields have a sharply peaked distribution with an average diameter of about 0.2 to $0.25 \mathrm{~mm}$.

The form of sand transport depends on different parameters. Main parameters are shear velocity and the weight of sand grains. Weight can be expressed by the diameter assuming the same density. An adequate measure to distinguish between transport mechanisms can be impressed according to the degree of detachment of the grains from the ground.

In [6] have been proposed three distinct types of sand transport induced by wind: creep, when the sand grains roll and slide along the surface. During this moment they stay in contact with the surface.

Next regime which could be distinguished is s.c. saltation, when the sand grains jump short distances within range of some centimeters. The entrainment, i.e. lifting of the grains originates in the shear stress of the air flow or in the impact of other sand grains descending again to the surface. Impacting sand grains transported by

saltation sometimes cannot reach sufficient velocity to enter into a new ballistic jump. So they are moving much shorter distances. This selected process is called reputation.

And finally-suspension, when the turbulent irregular movement of atmospheric layer is strong enough to keep the sand grains aloft. They are transported over long distances.

Consider the model for dunes motion which is based

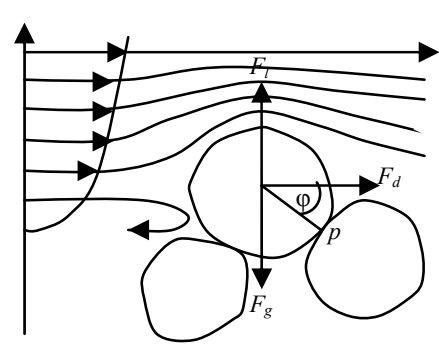

Fig.1 - The grain starts to role when the drag and lift force exceed the gravitational force. This can be expressed by a momentum balance with respect to the pivot point $p$. on momentum balance (sketch is shown on Fig.1)

Along this line the force to $\mathrm{Fl}$ gravity has to be introduced. The sand grain is approximated to be a sphere, so that

$$
F_{g}=\rho^{\prime} g \frac{\pi d^{3}}{6} .
$$

In what follow we would write an equation (first derived in [6]) for the threshold of entrainment, i.e. the minimum shear stress of wind at which it will de able to lift a sand grain from the surface. Therefore the momentum balance of rotating the upper sand grain around its touching point $p$ (Fig.1) can be expressed as

$$
F_{d} \frac{d}{2} \cos \varphi=\left(F_{g}-F_{l}\right) \frac{d}{2} \sin \varphi,
$$

where $\varphi$ is the angle between vertical direction and the line pointing from the sand grain center to $\mathrm{p}$. After use (4) we would get so called fluid threshold (or aerodynamic entrainment threshold) $\tau_{t \alpha}$

$$
\frac{\tau_{t \alpha}}{\rho^{\prime} g d}=\frac{2}{3 \beta}\left(\frac{\sin \varphi}{\cos \varphi+c \sin \varphi}\right) .
$$

So the parameters of the threshold, the grain diameter $\mathrm{d}$ and the immersed density $\rho^{\prime}$, are directly proportional to the shear stress. The angle $\varphi$ can be interpreted as a parameter of the packing of the grains, $\beta$ is determined by shape and sorting.

After [7] the right hand side of Eq.(6) can be called a dimensionless coefficient $\Theta$ (Shields parameter). It ranges from 0.01 to 0.014 for high Reynolds numbers. After using the expression for the shear velocity $u_{*}=\sqrt{\tau / \rho_{\text {air }}}$, equation (6) defines the fluid threshold shear velocity $u_{* t \alpha}$, 


$$
u_{* t \alpha}=\sqrt{\Theta \frac{\rho^{\prime} g d}{\rho_{\mathrm{air}}}} .
$$

The derivation given upper holds only for sand grains which have a diameter that is large enough to neglect cohesive and repulsive forces between the grains. This is valid for a diameter larger than $0.2 \mathrm{~mm}$. Inserting typical values into Equation (7), $u_{* t \alpha}$ allow us to reach a shear velocity of $u_{* t \alpha}=0.25 \mathrm{~ms}^{-1}$.

Nevertheless this value is valid only for entrainment of sand grains into air. When there are already grains entrained, i.e. the air flow is transporting sand. Then the impacting sand grain gives large momentum transfer to a resting grain on the bed. Thus the threshold value gets lower. It is called impact threshold $u_{* t}$. Still the expression of Equation (7) keeps valid but with the modification of an effective Shields parameter $\Theta=0.0064$. In the turbulent wind regime $\mathrm{s}$ over dune surface fluctuations can determine shear velocities which exceed the entrainment threshold. That is why sand transport can be maintained for shear velocities between $u_{* t \alpha}$ and $u_{* t}$. Given estimations of a single threshold are getting difficult for poorly sorted sediments. Moisture and cementing neither have been included. On the other side the threshold is changing at inclined surfaces. Gravity directs into another direction. Rigorously speaking this effect should be included in the momentum balance (5).

Therefore sand grains are entrained directly from the sand bed for a shear stress higher than the fluid threshold shear stress $\tau_{t \alpha}$. The linear model [8] proposes the number of entrained grains proportional to excess shear stress,

$$
N_{a}=\zeta\left(\tau-\tau_{t a}\right),
$$

where $N_{a}$ is the number of entrained grains per time and $\zeta$ a proportionality constant. The direct entrainment gets important to begin the chain reaction leading to saltation like for example at places where the sand bed deigns, i.e. where downwind no sand supply is available.

Entrained grains in the air stream are exposed to the following forces. Aerodynamic forces lift and drag a sand grain. The gravitational force $\vec{F}_{g}$ obviously lets the trajectory end on the surface again. The drag force $\vec{F}_{d}$ accelerates in horizontal direction,

$$
\vec{F}_{d}=\frac{1}{2} \rho_{\text {air }} C_{d} \frac{\pi d^{2}}{4}(\overrightarrow{\mathrm{v}}(z)-\overrightarrow{\mathrm{u}})|\overrightarrow{\mathrm{v}}(z)-\overrightarrow{\mathrm{u}}|
$$

where $\mathrm{d}$ is the grain diameter, $\overrightarrow{\mathrm{v}}(z)$ - the velocity of the air, $\overrightarrow{\mathrm{u}}$ - the velocity of the grain, and $\mathrm{C}_{\mathrm{d}}-$ the drag coefficient that depends on the local value of Reynolds number $\operatorname{Re}=|\overrightarrow{\mathrm{v}}(z)-\overrightarrow{\mathrm{u}}| d / v$. As it was shown in [9], the lift force has remarkable effects only a few grain diameters away from ground and therefore it is convenient to include the effects of the lift force in the initial.

The reaction of the sand bed to the impact of a sand grain is of rather complex nature. The splash process comprises the interaction between the sand grain and the grains in the vicinity of the impact. Thus many grains can be involved in this process. Numerical modeling and experimental studies have been made in [9]. Mainly the splash process is described in a stochastic way. It is divided into the following three different resulting situations. First the incoming sand grain distributes its momentum to the sand bed so that no other grain gains sufficient energy to leave the ground. Secondly, the grain rebounces loosing some of its energy. Thirdly, the incoming grain distributes its energy so that one or more grains can leave the bed. The splash process is described by the splash function $S\left(u_{i}, \varphi_{i}, \theta_{i}, u_{e}, \varphi_{e}, \theta_{e}\right)$. It defines the probability to dislodge a grain with a certain angle $\varphi_{e}, \theta_{e}$ and velocity $u_{e}$ due to an impacting grain with an angle $\varphi_{i}, \theta_{i}$ and velocity $u_{i}$. Regarding the angles $\theta$ to be the angles determining horizontal directions they vary only due to lateral diffusion. That means that they result to zero in average. For the saltation transport here described it is found an impact angle with respect to the sand bed from $10^{\circ}$ to $15^{\circ}$.

Different approaches to describe saltation in a macroscopic way have been made. They are not properly connected with the microscopic processes explained upper. Required macroscopic variable is the send flux $q$ (which means the sand flux per unit width and time). This sand flux depends on the shear velocity $u_{*}$, the threshold $u_{* t}$, the grain diameter $\mathrm{d}$ and others. In the following relations history and transients out of non-equilibrium conditions are not considered. Hence, they describe the equilibrium state where the sand flux is saturated.

Measurement in wind tunnels showed that for shear velocities $u_{*}>>u_{* t}$ the sand flux scales with the cube of the shear velocity $\left(q \propto u_{*}^{3}\right)$. Near the shear threshold the situation seems to be much more complicated. Still there are differences between empirical and theoretical flux estimations. One possible relation proposing the cubic proportionality is

$$
q_{B}=C_{B} \frac{\rho_{\mathrm{air}}}{g} \sqrt{\frac{d}{D}} u_{*}^{3},
$$

where $\mathrm{d}$ is the grain diameter and $D=250 \mu \mathrm{m}-\mathrm{a}$ reference grain diameter. To include the fact that under a certain threshold the shear stress is not strong enough to 
keep saltation transport many other phenomenological sand flux relations have been made. The widely used expression was mentioned, for instance, in [9]

$$
q_{L}=C_{L} \frac{\rho_{\mathrm{air}}}{g} u_{*}^{2}\left(u_{*}-u_{* t}\right),
$$

where $C_{L}$ is a fit parameter.

Other attempts to average the microscopic processes contained more information about sand transport one can find in $[10,11]$. In [11] has been performed the following relation,

$$
q_{S}=C_{S} \frac{\rho_{\text {air }}}{g} u_{*}\left(u_{*}-u_{* t}\right)\left(u_{*}+7.6 u_{* t}+2.05 m s^{-1}\right),
$$

where $C_{S}$ is an analytically determined parameter.

Relevant experimental data is reproduced quite well with this functional structure. Important question is how the system behaves in non-equilibrium states which still have not reached the saturation state. Numerical simulations on the grain scale showed that the system needs about two seconds to reach the equilibrium state for a flat surface. This matches quite well with experimental data by wind tunnel measurements. A macroscopic continuum saltation model was proposed recently that includes saturation transients and for the other scalar quantities

$$
\phi=\bar{\phi}+\phi^{\prime}
$$

where $\bar{\phi}$ and $\phi^{\prime}$ are the mean and fluctuating parts, denotes for example pressure $p$ or energy.

After use given upper argumentation with the help of Navier-Stoces equations and taking a time or ensemble average one can obtain the following set:

$$
\begin{gathered}
\frac{\partial \rho}{\partial t}+\frac{\partial}{\partial x_{i}}(\rho u)=0 \\
\rho \frac{d u_{i}}{d t}=-\frac{\partial \rho}{\partial x_{i}}+\frac{\partial}{\partial x_{i}}\left[\mu\left(\frac{\partial u_{i}}{\partial x_{j}}+\frac{\partial u_{j}}{\partial x_{i}}-\frac{2}{3} \delta_{i j} \frac{\partial u_{l}}{\partial x_{l}}\right)\right]+ \\
+\frac{\partial}{\partial x_{i}}\left(-\rho\left\langle u_{i}^{\prime} u_{j}^{\prime}\right\rangle\right),
\end{gathered}
$$

Equations (14) and (15) can be called Reynolds averaged Navier-Stoces equations. Their only difference to the outgoing Navier-Stoces equations are the additional terms of the Reynolds stresses $\frac{\partial}{\partial x_{i}}\left(-\rho\left\langle u_{i}^{\prime} u_{j}^{\prime}\right\rangle\right)$. A relation of these to the mean velocity gradients comprises the Boussinesq hypothesis

$$
-\rho\left\langle u_{i}^{\prime} u_{j}^{\prime}\right\rangle=\mu_{t}\left(\frac{\partial u_{i}}{\partial x_{j}}+\frac{\partial u_{j}}{\partial x_{i}}\right)-\frac{2}{3}\left(\rho k+\mu_{t} \frac{\partial u_{i}}{\partial x_{i}}\right) \delta_{i j},
$$

where $k$ is the kinetic energy and $\mu_{t}$ - the turbulent viscosity. The Boussinesq hypothesis contains the small inconsistency that $\mu_{t}$ is assumed to be isotropic and scalar which is not strictly true. $k$ and $\mu_{t}$ can be calculated for example with the semi-empirical $k$-e model of Launder and Spalding. There the turbulent kinetic energy $k$ and the turbulence dissipation rate $e$ are calculated by two differential equations. The turbulent viscosity finally is obtained by

$$
\mu_{t}=\rho C_{\mu} \frac{k^{2}}{e},
$$

where $C_{\mu}=0.09$ is a constant, determined by experiments with air and water.

\section{SOME MODEL RESULTS}

It was shown in [12] that there appears a large eddy in the lee side after the sharp brink of a dune. A separation of the quasi-laminar flow which is also found at the windward side and the turbulent eddy holds over a long distance after the brink. The separation streamline reaches from the point of flow separation (the brink) to the point of re-attachment at a distance of approximately six times the height of the brink. The surface formed by the separation streamlines is called separation bubble $\mathrm{s}(\mathrm{x})$. According to [9] the air shear stress $\tau(x, y)$ on the windward side of the dune can be calculated using the envelope that comprises the dune and the barchans' dunes showed that between the horns of a barchan only a negligible amount of sediment transport occurs. That means that the shear stress $\tau(x, y)$ in the separation bubble be set to zero.

Hence, the envelope surface $\tilde{h}(x, y)$ is used for the calculation of the air shear stress over a dune. The functional form for a separation bubble is obtained by the minimal heuristic ansatz of a polynomial of third order. Therefore the dune surface is cut into slides in the wind direction where every slide has its own separation streamline $\mathrm{s}(\mathrm{x})$. The condition of smoothness determines already three parameters of the polynomial as the height of the brink $s(0)=h_{0}^{\prime}$, the wind ward slope at the brink has to coincide with the separation streamline's first point $s^{\prime}(0)=h_{0}^{\prime}$ and the height and slope are zero at the reattachment point $s\left(L_{r}\right)=0, s^{\prime}\left(L_{r}\right)=0$ (assuming that the separation streamline ends on the ground), i.e.:

$$
\begin{aligned}
& s(x)=a_{3} x^{3}+a_{2} x^{2}+h_{0}^{\prime} x+h_{0}, \\
& a_{3}=\left(2 h_{0}+h_{0}^{\prime} L_{r}\right) L_{r}^{-3}, \\
& a_{2}=-\left(3 h_{0}+2 h_{0}^{\prime} L_{r}\right) L_{r}^{-2} .
\end{aligned}
$$


The downwind distance $L_{r}$ is determined by phenomenological observations. According to [12] a good estimate is given by setting the maximum slope of the separation streamline equal to $C=0.25\left(14^{\circ}\right)$. A second-order approximation yields finally the equation for the length of the separation streamline,

$$
L_{r}=\frac{3 h_{0}}{2 C}\left(1+\frac{1}{4} \frac{h_{0}^{\prime}}{C}+\frac{1}{8}\left(\frac{h_{0}^{\prime}}{C}\right)^{2}\right) .
$$

For simulations of dune fields and of dunes which localize on a field sand bed the separation streamlines do not connect smoothly to the height profile but intersect the surface at a distance smaller than $L_{r}$ after a brink. The height $h_{1}$ and the slope $h_{1}^{\prime}$ at the intersection point at $x=x_{1}=x_{0}+L$ now substitute the parameters $s\left(L_{r}\right)=0$ and $s^{\prime}\left(L_{r}\right)=0$, respectively. Hence, the new separation streamline is calculated according to

$$
\begin{aligned}
& s_{n}(x)=a_{3} x^{3}+a_{2} x^{2}+h_{0}^{\prime} x+h_{0}, \\
& a_{2}=-\left(3 h_{1}-h_{1}^{\prime} x+2 h_{0}^{\prime} x_{1}-3 h_{0}\right) L^{-2}, \\
& a_{3}=\left(h_{1}^{\prime} L-2 h_{1}+h_{0}^{\prime} L_{r}+2 h_{0}\right) L^{-3} .
\end{aligned}
$$

Using the concept of the separation bubble the shear stress of the wind over a dune can be calculated with an algorithm which is valid for smooth surfaces. The most suitable layer for this purpose should be the shear stress layer. In [13] has been obtained the following shear stress perturbation in wind direction for a smooth hill

$$
\begin{aligned}
& \tilde{\tau}_{x}\left(k_{x}, k_{y}\right)=\frac{h\left(k_{x}, k_{y}\right) k_{x}^{2}}{|k|} \frac{2}{U^{2}(l)} \times \\
& \times\left(1+\frac{2 \ln L\left|k_{x}\right|+4 \gamma+1+i \operatorname{sign}\left(k_{x}\right) \pi}{\ln l / z_{o}}\right),
\end{aligned}
$$

and for the shear stress perturbation in lateral direction

$$
\tilde{\tau}_{x}\left(k_{x}, k_{y}\right)=\frac{h\left(k_{x}, k_{y}\right) k_{x} k_{y}}{|k|} \frac{2}{U^{2}(l)},
$$

where $|k|=\sqrt{k_{x}^{2}+k_{y}^{2}}$ and $\gamma=0.577216$ (Euler's constant). Equations (21) and (22) are taken in Fourier space with the wave number $k_{x}$ and $k_{y} . U(l)$ is the normalized velocity of the undisturbed logarithmic profile at the height [14].

Strictly speaking [15] the governing equations for dunes motion has to be considered as model ones which came form local microscopic conservation laws.

\section{DIMENSIONLESS ANALYSIS OF DUNES MODELING}

Consider quantity $H_{j}$ to characterize the strength of the dunes motion event as their maximum height attained by the barchans. The absence of surface tension in granular media makes dimensional analysis even more tractable here than in the liquid case. The only other physical quantities of importance are: the individual grain diameter $D_{b}$, the impact velocity $U$, gravity $g$, along with material properties: the density of the sand $r_{s}$, the material (silica) $-r_{b}$, and finally the effective viscosity of the granular media me. For simplicity we can assume that the grain size $d_{s}$ only enters the problem through the effective viscosity. The dimensional analysis properly shows that the barchans height should follow an unknown function of only three dimensionless parameters

$$
H_{j} / D_{b}=\Phi\left(r_{p}, \mathrm{Re}, \mathrm{Fr}\right)
$$

i.e., a density ratio $r_{p}=\rho_{b} / \rho_{s}$, Reynolds number $\operatorname{Re}=\rho_{s} U D_{b} / \mu_{e}$, and a Froude number $\operatorname{Fr}=U / \sqrt{g D_{b}}$. The effective viscosity of flowing granular media remains an active topic of research and is far from fully characterized.

\section{CONCLUSIONS}

Particular study of this subject shows that phenomena governed more by compressive rather than shear stresses, therefore, the relevant model for sand motion (say, dunes) can be only a rough approximation.

Furthermore, note that with the typical definition of the effective granular viscosity, the Reynolds number simply reduces to a geometric factor $\operatorname{Re}=\frac{1}{2}\left(D_{b} / d_{s}\right)^{2}$, which is a constant for each grain size. The effective dynamic viscosity from the above formulas varies here in a range between 4 and 200 times that of water. The corresponding Reynolds numbers are between 1200 and 14000.

Dimensional analysis does not provide the form of the function F. However, using the above definition it is possible to show that the normalized dunes height collapses using a simple product of the Froude and Reynolds numbers. Instead of using the Reynolds number one could simply replace it by the dimensionless ratio $D_{b} / d_{s}$ in the above dimensional analysis. This would, however, obscure the effects of frictional dissipation, which clearly plays an important role in this process. Ignoring friction, one can construct a simple energy balance between the kinetic energy of the impacting $\rho_{b} D_{b}^{3} U^{2}$ and the potential energy of the dunes $\rho_{s} g d_{s}^{2} H_{j}^{2}$, where we assume the dunes thickness is proportional to $d_{s}$. This produces the following scaling 


$$
H_{j} / D_{b} \propto r_{p} \operatorname{Fr} \sqrt{\operatorname{Re}}
$$

In other words, was one to increase the grain diameter $d_{s}$ by a factor of $10 \sim$ i.e., reduce Re by 100 ! for the same impact conditions, then the frictionless flow would predict a 10-fold reduction in $H_{j}$, whereas the experiments suggest a 100 -fold reduction. This shows clearly that viscous forces play a role in the granular dunes formation (and their relevant dynamics), as well as gravity and inertia.

\section{REFERENCES}

1. Bagnold R.A. The size-grading of sand by wind. Proc. R. Soc. (Ser. A), 1937, no. 163, pp. 250-264.

2. Houghton J.T. The physics of atmospheres, 2nd edn. Cambridge: Cambridge Univ. Press., 1986.

3. Prandtl L. The mechanics of viscous fluids. Aerodynamic theory. Berlin: Springer, 1935, vol. III, pp. 34-208.

4. Friedman G.M., Sunders J.E. Principles of sedimentology. New York: Wiley, 1978, $439 \mathrm{p}$.

5. Pye K., Tsoar H. Aeolian sand and sand dunes. London: Unwin
Hyman, 1990

6. Sorensen M. Estimation of some aeolian sultation transport parameters from transport rate profiles. Proc. Int. Wkshp. Physics of Blown. Sand. Denmark, 1985, vol. I, pp. 141-190. In BarndorfNielsen et al (Eds).

7. Sorensen M. An analytic model of wind-blown sand transport. Acta Mechanica (Suppl.), 1991, no. 1, pp. 67-81.

8. Bagnold R.A. The movement of desert sand. Proc. R. Soc. (Ser. A), 1936 , no. 157 , pp. 594-620.

9. Zeman O., Jensen N.O. Progress report on modeling permanent form sand dunes. Risø National Laboratory M-2738, 1988.

10. Bagnold R.A. The nature of saltation and bed-load transport in water. Proc. R. Soc. (Ser. A), 1973, no. 332, pp. 473-504.

11. Shields A. Applications of similarity principles and turbulence research to bed-load movement. Technical Report Publ., no. 167, California Inst. Technol. Hydrodynamics Lab., 1936.

12. Herrmann H.J., Sauermann G. The shape of dunes. Physica A, 2000, no. 283, pp. 24-30.

13. Weng W.S., Hunt J.C.R., Carruthers D.J., Warren A., Wiggs G.F.S., Livingstone I., Castro I. Air flow and sand transport over sand-dunes. Acta Mechanica (Suppl.), 1991, no. 2, pp. 1-22.

14. Sauermann G., Rognon P., Polyakov A., Herrmann H.J. The shape of the barchan dunes of southern Morocco. Geomorphology, 2000, no. 36, pp. 47-62.

15. Kadanoff Leo P. Built upon sand: Theoretical ideas inspired by granular flows. Rev. Mod. Phys., 1999, no. 71, pp. 435.

\title{
ДО ТЕОРЕТИЧНОГО МОДЕЛЮВАННЯ РУХУ ПІЩАНИХ ДЮН
}

О.І. Герасимов, д.ф.-м.н.,

I.С. Андріанова, к.ф-м.н.

\author{
Одеський державний екологічний університет, \\ вул. Львівська, 15, 65016, Одеса, Украӥна, gerasymovoleg@gmail.com
}

Перенесення піску вітром представляє собою потужний ерозійний чинник, який впливає на створення та динаміку піщаних дюн ,а також завантажує атмосферу пиловими фракціями. У статті представлено стислий огляд фізики піску, що переноситься вітром. Зокрема розглянуто фізичну кінетику піщаних утворювань, формування і розвитку дюн та їхніх елементів. Також обговорюються деякі класи керуючих рівнянь, що описують фізику вітрового переносу піску і динаміку дюн,проблеми їх формулювання та розвязків.

Ключові слова: піщані дюни, вітровий потік, напруга зсуву, гранульована в'язкість.

\section{К ТЕОРЕТИЧЕСКОМУ МОДЕЛИРОВАНИЮ ДВИЖЕНИЯ ПЕСЧАНЫХ ДЮН}

О.И. Герасимов, д.ф.-м.н., И.С.Андрианова, к.ф-м.н.

Одесский государственный экологический университет, ул. Львовская, 15, 65016, Одесса, Украина, gerasymovoleg@gmail.com

Перенос песка ветром представляет собою мощную эрозийную силу, создающую песчаные дюны и рябь, и загружает атмосферу взвешенными пылевыми аэрозолями. В статье представлен краткий обзор физики переносимого ветром песка. В частности рассмотрена физика скачков песчаных гранул, формирования и развития песчаных дюн и гребней. Также обсуждаются некоторые классы управляющих уравнений, описывающих физику переносимого ветром песка и образования дюн.

Ключевые слова: песчаные дюны, ветровой поток, сдвиговое напряжение, гранулированная вязкость. 